\title{
Chikungunya Virus Infection Alters Expression of MicroRNAs Involved in Cellular Proliferation, Immune Response and Apoptosis
}

\author{
Anuj Sharma Nagaraja S. Balakathiresan Radha K. Maheshwari \\ Department of Pathology, Uniformed Services University of the Health Sciences, Bethesda, Md., USA
}

\author{
Key Words \\ Chikungunya $\cdot$ MicroRNA $\cdot$ Host response $\cdot$ \\ Cellular senescence $\cdot$ Topoisomerase
}

\begin{abstract}
Objective(s): Chikungunya virus (CHIKV) is a reemerging virus of significant importance that has caused large-scale outbreaks in the countries with a temperate climate. CHIKV causes debilitating arthralgia which can persist for weeks and up to a year. Fibroblast cells are the main target of CHIKV infection. In this study, we analyzed microRNA (miRNA) modulation in the fibroblast cells infected with CHIKV at an early stage of infection. Methods: 760 miRNAs were analyzed for modulation following infection with CHIKV at $6 \mathrm{~h}$ after infection. Bioinformatic analysis was done to identify the signaling pathway that may be targeted by the significantly modulated miRNAs. Validation of the miRNAs was done using a singleplex miRNA assay and protein target validation of modulated miRNAs was done by Western blot analysis. $\boldsymbol{R} \boldsymbol{e}-$ sults: Computational analysis of the significantly modulated miRNAs indicated their involvement in signaling pathways such as Toll-like receptor, mTOR, JAK-STAT and Pi3-Akt pathways, which have been shown to play important roles during CHIKV infection. Topoisomerase II $\beta$, a target of two of the modulated miRNAs, was downregulated upon CHIKV infec-
\end{abstract}

tion. Conclusion(s): We identified several miRNAs that may play important roles in early events after CHIKV infection and can be potential therapeutic targets against CHIKV infection.

(c) 2016 S. Karger AG, Basel

\section{Introduction}

Chikungunya is a reemerging infectious alphavirus disease which has caused large-scale outbreaks in Southeast Asia, islands surrounding the Indian Ocean, and most recently in the Caribbean [1-3]. The chikungunya virus (CHIKV) isolates with an E1-A226V mutation from recent outbreaks have shown enhanced pathogenesis and an expanded vector repertoire $[4,5]$. Adaptation of CHIKV to Aedes albopictus has made North America susceptible to the CHIKV emergence [2, 6]. In the United States of America, 37 states have seen travel-associated CHIKV cases, and Florida, Puerto Rico and the US Virgin Islands have reported locally transmitted cases of CHIKV (http://www.cdc.gov/chikungunya/geo/united-states. html). CHIKV causes debilitating arthritis which may last from a week up to a year $[6,7]$. CHIKV primarily causes peripheral tissues infection, but may also cause infection of the central nervous system, which is most severe in newborns followed by children and adults [7]. In the pe-

\section{KARGER 125\%}

(c) 2016 S. Karger AG, Base

$0300-5526 / 16 / 0585-0332 \$ 39.50 / 0$

E-Mail karger@karger.com

www.karger.com/int
Dr. Radha K. Maheshwar

4301 Jones Bridge Road

Bethesda, MD 20814 (USA)

E-Mail radha.maheshwari@usuhs.edu 
ripheral tissues, fibroblast cells of the muscle fascia, the connective tissue of joints and the dermis are the main targets of CHIKV infection [8]. CHIKV infection and disease spread in the host have been well characterized. However, the molecular mechanisms of CHIKV infection of fibroblasts are not very well understood $[2,6]$.

MicroRNAs (miRNAs) are small noncoding RNA molecules that regulate translation either by degradation or inhibition of translation of the target mRNA transcripts. miRNAs have been shown to play important roles in several viral infections [9-14], and miRNA modulation in CHIKV-infected primary fibroblast cells has been reported to be related to the induction of TGF- $\beta$ and downregulation of anaphase-promoting complex genes [4]. In this study, we tested miRNA modulation in mouse fibroblast cells early after the infection to identify pathways that are targeted by the CHIKV immediately after the infection. Topoisomerase II $\beta$ (Top2b) was identified as one of the target molecules of the modulated miRNAs and was found to be downregulated after CHIKV infection. The data presented in this study enhance our understanding of CHIKV infection and identify miRNAs that may play a critical role in inhibiting cellular transcription, thereby helping in establishing virus replication in the host cells.

\section{Materials and Methods}

Virus, Cell Culture and Infection

Sucrose gradient-purified live-attenuated strain of CHIKV, CHIKV 181/25, was used in the present study. The virus was kindly provided by Dr. Parker of USAMRIID in Frederick, Md., USA. CHIKV 181/25 was taken as it replicates well in fibroblast cells and can be safely handled at biosafety level 2 . The mouse fibroblast $\mathrm{L}$ cells (ATCC, Manassas, Va., USA) were cultured at $37^{\circ}$ and $5 \% \mathrm{CO}_{2}$ in the growth media consisting of $1 \times$ minimum essential medium with Earle's salts and L-glutamine (VWR, Radnor, Pa., USA) supplemented with $10 \%$ newborn calf serum and $1 \%$ pen/strep solution (Lonza, VWR, Radnor, Pa., USA). The cells were infected by incubating with virus suspension for $1 \mathrm{~h}$ at $37^{\circ}$ and $5 \% \mathrm{CO}_{2}$. After $1 \mathrm{~h}$, virus suspension was removed and the cells were washed once with $1 \times$ phosphate-buffered saline (PBS) followed by addition of fresh growth media and incubation at $37^{\circ}$ and $5 \% \mathrm{CO}_{2}$. The control mockinfected cells were similarly treated with only $1 \times$ PBS. The virus titer was measured as $50 \%$ tissue culture infectivity dose $\left(\mathrm{TCID}_{50} / \mathrm{ml}\right)$.

\section{RNA Isolation}

Total cellular RNA including miRNAs was isolated from $150 \mu \mathrm{l}$ of cells infected with MOI $=1(n=3)$ or uninfected controls $(n=$ 3) using miRNeasy serum/plasma kit (Qiagen, Gaithersburg, Md., USA) as per manufacturer protocol. The amount of miRNA in each of the total RNA sample was quantitated using Agilent Small RNA Kit on a 2100 Bioanalyzer instrument (Agilent Technologies, Santa Clara, Calif., USA). The miRNA concentration in each of the samples was then used for the miRNA expression analysis.

Chikungunya Alters Host miRNA

Expression
miRNA Analysis

The miRNA expression profile was evaluated using the TaqMan ${ }^{\circledR}$ MicroRNA Low-Density Rodent Array (TLDA) version 2.0 platform as described earlier [8]. The TLDA platform can analyze 760 miRNAs in a set of two 384-well plates, namely plate A and plate B. All TaqMan ${ }^{\circledR}$ products were purchased from Life Technologies (Grand Island, N.Y., USA). Briefly, a reverse transcription (RT) reaction was done with 200 ng of miRNA using a TaqMan ${ }^{\circledR}$ miRNA RT kit. For each sample, i.e. cells infected with MOI = 1 $(\mathrm{n}=3)$ and uninfected controls $(\mathrm{n}=3)$, two separate RT reactions were carried out using either Megaplex RT Rodent Primer pool A or pool B (Life Technologies, Grand Island, N.Y., USA). The RT reaction $\left[\left(16^{\circ} / 2 \mathrm{~min}, 42^{\circ} / 1 \mathrm{~min}, 50^{\circ} / 1 \mathrm{~s}\right) \times 40\right.$ cycles, $85^{\circ} / 5 \mathrm{~min}$, and hold at $4^{\circ}$ ] was carried out using a Veriti ${ }^{\circledR}$ 96-Well Thermal Cycler (Life Technologies, Grand Island, N.Y., USA). RT was followed by preamplification of the RT product. Each preamplification reaction consisted of $5 \mu \mathrm{l}$ of RT product (pool A or pool B) + $12.5 \mu \mathrm{l}$ of $\mathrm{TaqMan}^{\circledR}$ PreAmp Master Mix $+2.5 \mu \mathrm{l}$ of respective Megaplex PreAmp rodent primer (pool A or pool B) $+5 \mu$ l of nuclease-free water. Preamplification reaction $\left[95^{\circ} / 10 \mathrm{~min}, 55^{\circ}\right.$ $2 \mathrm{~min}, 72^{\circ} / 2 \mathrm{~min}\left(95^{\circ} / 15 \mathrm{~s}, 60^{\circ} / 4 \mathrm{~min}\right) \times 14$ cycles, $99.9^{\circ} / 10 \mathrm{~min}$, and hold at $4^{\circ}$ ] was carried out on a Veriti ${ }^{\circledR} 96$-Well Thermal Cycler (Life Technologies, Grand Island, N.Y., USA). For the miRNA profile, $9 \mu$ l of preamplification reaction (pool A or pool B) product was mixed with $450 \mu \mathrm{l}$ of TaqMan ${ }^{\circledR}$ Universal Master Mix, and $441 \mu \mathrm{l}$ of nuclease-free water. $100 \mu \mathrm{l}$ of this mix was loaded in each of the 8 lanes of the respective TaqMan ${ }^{\circledR}$ Rodent miRNA Array Set Version 2.0 cards. PCR reaction $\left[94.5^{\circ} / 10 \mathrm{~min}\left(97.0^{\circ} / 30 \mathrm{~s}, 59.7^{\circ}\right.\right.$ $1 \mathrm{~min}) \times 40$ cycles] was done using a $7900 \mathrm{HT}$ fast real-time PCR machine (Life Technologies, Carlsbad, Calif., USA).

Expression of individual miRNAs was validated using the TaqMan ${ }^{\circledR}$ miRNA assays (Life Technologies, Carlsbad, Calif., USA) in each sample, i.e. infected $(n=3)$ and uninfected controls $(n=3)$. U6 small nuclear RNA (U6 snRNA) was used as endogenous controls. Real-time quantitative RT-PCR (qRT-PCR) was performed on $200 \mathrm{ng}$ of miRNA as per the manufacturer's protocol.

\section{miRNA Data Analysis}

miRNA expression analysis was done using real-time StatMiner ${ }^{\circledR}$-qPCR Data Analysis Software version 5.0 (Intergromics ${ }^{\circledR}$; Life Technologies, Grand Island, N.Y., USA). C $\mathrm{t}_{\mathrm{t}}$ values of the miRNAs were ported into the Statminer software. The following settings were used to conduct the data analysis. For each sample, data from cards A and B were merged and samples were grouped as infected and uninfected. Imputation for the missing value was skipped and data were filtered for ' $\mathrm{C}_{t}<36$ ' and ' 1 or more failure in 3 replicates'. Therefore, miRNAs that show $C_{t} \geq 36$ in any of the three replicate samples were flagged as 'not expressed'. miRNAs with all three replicates showing $C_{t}<36$ were labeled as 'expressed'. Normalization of the data was done using the endogenous U6 snRNA. To reduce the false discovery rate, the final data were filtered for an adjusted $\mathrm{p}$ value (Benjamini-Hochberg method) $\leq 0.05$ and fold difference $\geq 2.0$.

Computational analysis of the miRNA expression data was done by DNA Intelligent Analysis (DIANA)-miRPath, Ingenuity Pathway Analysis (IPA) and TargetScan software. The combined effect of the miRNA gene targets on the Kyoto Encyclopedia of Genes and Genomes (KEGG) pathways was evaluated by DIANAmiRPath software [15]. IPA was used to analyze the correlation of the validated targets of miRNA to cellular proliferation and repli- 
Fig. 1. CHIKV replication in L cells: $\mathrm{L}$ cells were infected with $\mathrm{MOI}=1(\mathrm{n}=3$ each time point) or MOI $=10(\mathrm{n}=3$ each time point), and virus titer was measured as $\mathrm{TCID}_{50} / \mathrm{ml}$ in the cell supernatant at predetermined time points. Values are presented as means \pm SEM.
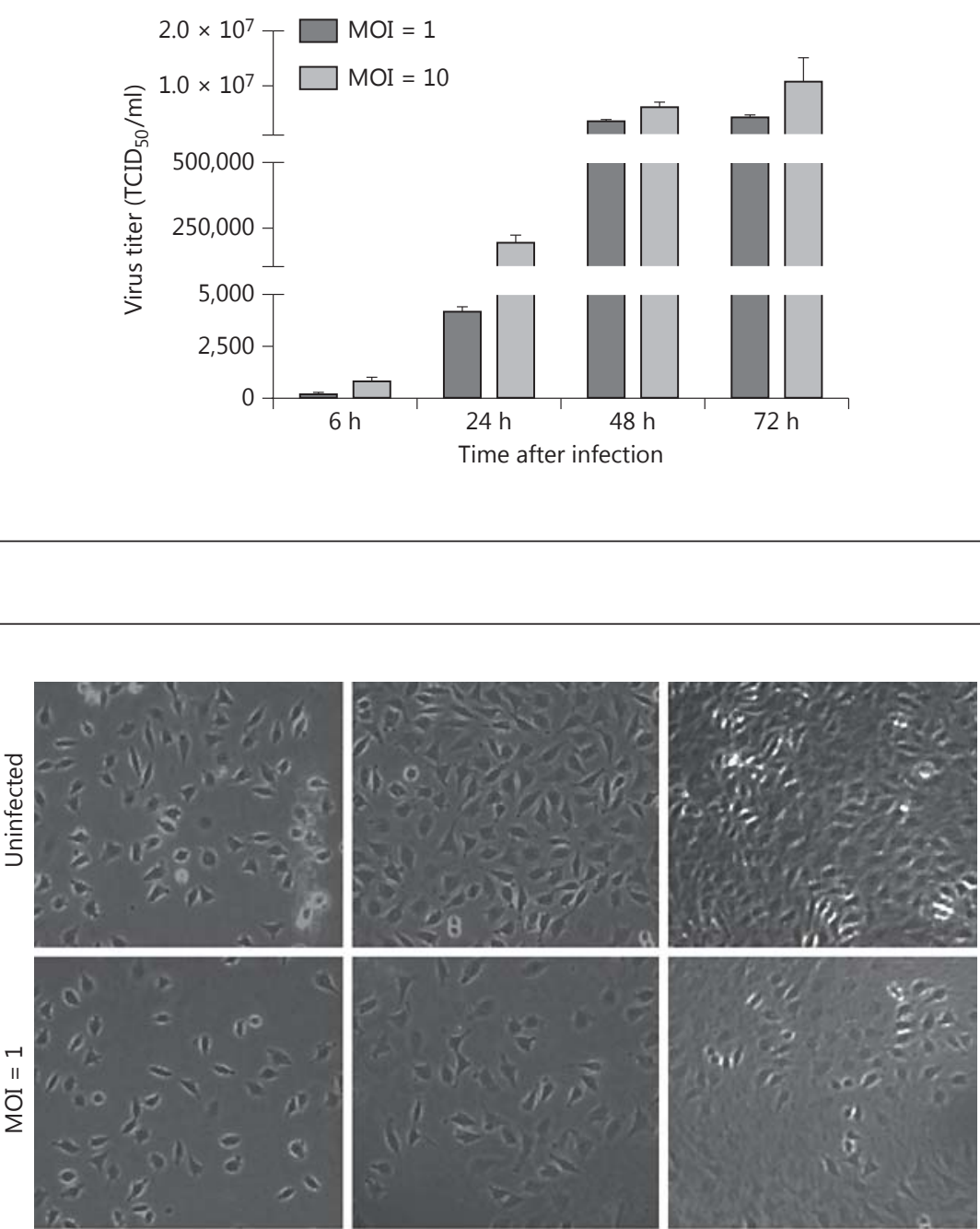

Fig. 2. CPE in CHIKV-infected cells: L cells were infected with either MOI $=1(n=3)$ or $10(\mathrm{n}=3)$, and cells were observed for CPE after infection. No CPE was observed in cells infected with MOI $=1$ until $72 \mathrm{~h}$. CPE-like rounding of cells (arrows) was observed in the cells infected with MOI = 10 at $72 \mathrm{~h}$ after infection. Also note the reduction in cell density in the cells infected at 48 and $72 \mathrm{~h}$ after infection when compared to the uninfected controls $(n=2)$. These results are representative of repeat experiments.

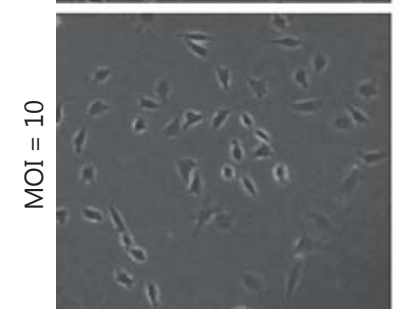

$24 \mathrm{~h}$

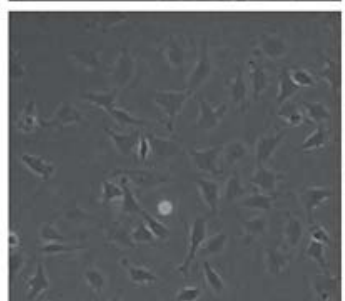

$48 \mathrm{~h}$

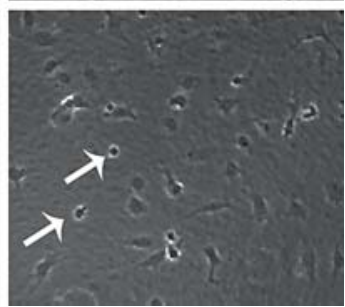

$72 \mathrm{~h}$ cation, apoptosis and Jak-STAT signaling pathways. TargetScan was used to identify the binding sites of miRNA in the $3^{\prime} U T R$ region of the target gene.

\section{Cytopathic Effect and Nuclear Staining}

L cells were plated in 8-chamber slides (EMD Millipore, Billerica, Mass., USA) at a density of 6,000 cells/well. Cells were either infected with CHIKV $181 / 25$ at an MOI $=1(n=3)$ or MOI $=10$ $(\mathrm{n}=3)$. Unabsorbed virus was removed by washing the cells once with sterile $1 \times$ PBS (EMD Millipore, Billerica, Mass., USA) and replenishing with fresh growth media. At each predetermined time point, chambers were removed and slides were immediately fixed in an ice-cold acetone:methanol (1:1) solution for $10 \mathrm{~min}$ followed by washing two times in $1 \times$ PBS. Slides were then mounted using Vectashield mounting medium with DAPI $\left(4^{\prime}, 6\right.$-diamidino2-phenylindole; Vector, Burlingame, Calif., USA) and stored at $4^{\circ}$. 
Table 1. miRNA modulation by CHIKV infection at $6 \mathrm{~h}$ after infection

\begin{tabular}{|c|c|c|c|c|c|c|c|}
\hline No. & miRNA & $\begin{array}{l}\text { Relative fold } \\
\text { expression }\end{array}$ & $\begin{array}{l}\text { Adjusted } \\
\mathrm{p} \text { value }\end{array}$ & No. & miRNA & $\begin{array}{l}\text { Relative fold } \\
\text { expression }\end{array}$ & $\begin{array}{l}\text { Adjusted } \\
\text { p value }\end{array}$ \\
\hline \multicolumn{4}{|c|}{ Expression not detected in infected } & 53 & mmu-miR-99b-3p & 2.81 & $3.86 \mathrm{E}-03$ \\
\hline 2 & mmu-miR-30c-1-3p & $1.00 \mathrm{E}-04$ & $1.39 \mathrm{E}-06$ & 55 & mmu-miR-294-3p & 2.92 & $6.38 \mathrm{E}-03$ \\
\hline \multicolumn{4}{|c|}{ Expressed in both uninfected and infected } & 56 & mmu-miR-451a & 3.01 & $2.49 \mathrm{E}-03$ \\
\hline 3 & mmu-miR-376c-3p & 0.05 & $3.64 \mathrm{E}-02$ & 57 & mmu-miR-295-3p & 3.04 & $3.82 \mathrm{E}-04$ \\
\hline 5 & mmu-miR-466b-3p & 1.96 & $3.28 \mathrm{E}-02$ & 59 & mmu-miR-465a-3p & 3.15 & $2.88 \mathrm{E}-02$ \\
\hline 6 & mmu-miR-486a & 1.98 & $3.72 \mathrm{E}-03$ & 60 & mmu-miR-181a-5p & 3.17 & $1.02 \mathrm{E}-03$ \\
\hline 7 & mmu-miR-350-3p & 1.98 & $8.31 \mathrm{E}-03$ & 61 & rno-miR-20a-3p & 3.18 & $1.09 \mathrm{E}-02$ \\
\hline 8 & rno-miR-30d-3p & 1.99 & $5.55 \mathrm{E}-03$ & 62 & $\mathrm{mmu}-\mathrm{miR}-877-3 \mathrm{p}$ & 3.20 & $4.10 \mathrm{E}-04$ \\
\hline 9 & mmu-miR-194-1 & 2.00 & $6.48 \mathrm{E}-03$ & 63 & mmu-let-7b-5p & 3.20 & $4.08 \mathrm{E}-04$ \\
\hline 10 & mmu-miR-149-5p & 2.00 & 8.79E-04 & 64 & mmu-let-7a-5p & 3.22 & $1.31 \mathrm{E}-03$ \\
\hline 15 & mmu-miR-292a-3p & 2.06 & $6.80 \mathrm{E}-03$ & 69 & mmu-miR-200a-3p & 3.86 & $1.11 \mathrm{E}-04$ \\
\hline 16 & mmu-miR-7b-5p & 2.07 & $1.61 \mathrm{E}-02$ & 70 & rno-miR-664-3p & 4.16 & $1.10 \mathrm{E}-02$ \\
\hline 17 & mmu-miR-29b-1-5p & 2.07 & $9.48 \mathrm{E}-03$ & 71 & mmu-miR-181c-5p & 4.18 & $1.18 \mathrm{E}-04$ \\
\hline 18 & mmu-miR-132-3p & 2.07 & $2.92 \mathrm{E}-03$ & 72 & mmu-miR-883b-3p & 4.83 & $9.82 \mathrm{E}-03$ \\
\hline 19 & mmu-miR-466a-3p & 2.07 & $2.25 \mathrm{E}-02$ & 73 & mmu-miR-139-5p & 6.84 & $2.92 \mathrm{E}-04$ \\
\hline 20 & mmu-miR-7a-1-3p & 2.09 & $1.53 \mathrm{E}-03$ & 74 & mmu-miR-378a-3p & 11.66 & $7.84 \mathrm{E}-03$ \\
\hline 21 & mmu-miR-546 & 2.14 & $4.80 \mathrm{E}-02$ & 75 & mmu-miR-409-3p & 15.76 & $1.28 \mathrm{E}-04$ \\
\hline
\end{tabular}

$4.29 \mathrm{E}-03$

$3.03 \mathrm{E}-04$

$1.09 \mathrm{E}-02$

4.42E-02

$1.39 \mathrm{E}-02$

$1.21 \mathrm{E}-04$

$2.59 \mathrm{E}-03$

$2.01 \mathrm{E}-02$

$2.76 \mathrm{E}-03$

$1.79 \mathrm{E}-02$

$8.79 \mathrm{E}-04$

$3.99 \mathrm{E}-03$

$2.20 \mathrm{E}-03$

$4.08 \mathrm{E}-03$

$1.19 \mathrm{E}-04$

$4.22 \mathrm{E}-04$

$5.61 \mathrm{E}-04$

$1.10 \mathrm{E}-02$

7.97E-04

$2.13 \mathrm{E}-03$

$2.45 \mathrm{E}-03$

$5.89 \mathrm{E}-04$

$1.83 \mathrm{E}-03$

$1.27 \mathrm{E}-03$

$1.11 \mathrm{E}-03$

$2.22 \mathrm{E}-02$

$1.83 \mathrm{E}-03$

$1.10 \mathrm{E}-04$

$4.03 \mathrm{E}-03$

$1.61 \mathrm{E}-04$
The cytopathic effect (CPE), i.e. rounding or loss of normal morphology of cells, and DAPI staining were evaluated by bright field and fluorescent microscopy, respectively.

\section{Protein Analysis}

$\mathrm{L}$ cells were plated in 12 -well plates and infected with CHIKV $181 / 25$ at either MOI $=1(n=2)$ or MOI $=10(n=2)$, or mockinfected controls $(n=2)$. At the predetermined time point of 24 , 48 and $72 \mathrm{~h}$, cells supernatants were removed and total cellular protein was collected by using RIPA buffer (G Biosciences, St. Louis, Mo., USA) containing phosphatase and protease inhibitors (Roche Diagnostics Corp., Indianapolis, Ind., USA). Total protein in the samples was quantitated using the Pierce BCA Protein Assay Kit (Thermo Fisher Scientific, Rockford, Ill., USA). Protein quality (10 ng of total protein) was assessed by SDSPAGE followed by Coomassie Blue staining. For Top2b evaluation, $10 \mathrm{ng}$ of the total protein from each sample was run on a Novex ${ }^{\circledR} 4-12 \%$ bis-tris gel (Life Technologies, Grand Island, N.Y., USA) and proteins were transferred to an Amersham Hybond-ECL nitrocellulose membrane (GE Healthcare Bio-Sciences, Pittsburg, Pa., USA) at $90 \mathrm{~V}$ for $90 \mathrm{~min}$. The membrane was blocked using 5\% nonfat dry milk (Santa Cruz Biotechnology, Inc., Dallas Tex., USA), followed by overnight incubation with 10 $\mathrm{ml}$ of 1:100 diluted rabbit anti-mouse-Top2b primary antibody (Santa Cruz Biotechnology Inc., Dallas Tex., USA) at $4^{\circ}$. The alkaline phosphatase-conjugated goat anti-rabbit secondary IgG (1:10,000 dilution; EMD Millipore, Billerica, Mass., USA) was 
used to bind to the primary antibody for $2 \mathrm{~h}$ at room temperature. A blot was developed using $10 \mathrm{ml}$ of the Western Blue ${ }^{\circledR}$ stabilized substrate for alkaline phosphatase (Promega, Madison, Wis., USA) for 10-12 min at room temperature. This experiment was repeated twice.

\section{Results}

\section{CHIKV Infection Modulates miRNA}

Cellular events immediately after the infection of alphaviruses are important in determining the outcome of infection [16]. Therefore, the miRNA profile was evaluated $6 \mathrm{~h}$ after infection to detect early changes in the host miRNA modulation due to CHIKV infection but not its active replication/release. L cells were infected with MOI1 and virus replication was measured as virus titer in the cell supernatant (fig. 1). No CPE was observed in the cells until $72 \mathrm{~h}$ after infection (fig. 2); however, CHIKV-specific RT-PCR showed viral transcripts in infected cells (fig. 3a) indicating establishment of CHIKV infection in the cells within $6 \mathrm{~h}$ after infection. The overall expression of miRNAs among the biological replicates $(n=3)$ showed a greater than $96 \%$ correlation. The average number of miRNAs expressed in infected and uninfected cells was not significantly different (fig. 3b). However, hierarchical clustering of the expression patterns of miRNAs clearly distinguished the uninfected from the infected samples (fig. 3c). Out of $760 \mathrm{miRNAs}$ probed, $75 \mathrm{miRNA}$ were found to be significantly modulated after CHIKV infection, i.e. $>2$-fold modulation (adjusted $\mathrm{p} \leq 0.05$ ). Four miRNAs were downregulated and 71 miRNAs were found to be significantly upregulated in the infected cells (fig. 3d; table 1).

\section{Signaling Pathway Analysis of Significantly \\ Modulated miRNA}

KEGG pathway analysis of the significantly modulated miRNAs was done using the DIANA-miRPath software [15]. $106 \mathrm{KEGG}$ pathways were identified to be significantly modulated by the combined effect of the modulated miRNAs. Selected KEGG pathways based on signaling and cellular processes are given in figure 4 . Additional core analysis of the significantly modulated miRNAs using IPA software indicated their effect on the cellular proliferation and replication pathways (online suppl.fig. 1;seewww.karger.com/doi/10.1159/000441309 for all online suppl. material). Apoptosis and Jak-STAT signaling pathways have been shown to play important roles in CHIKV infection [17-20]. Functional pathway

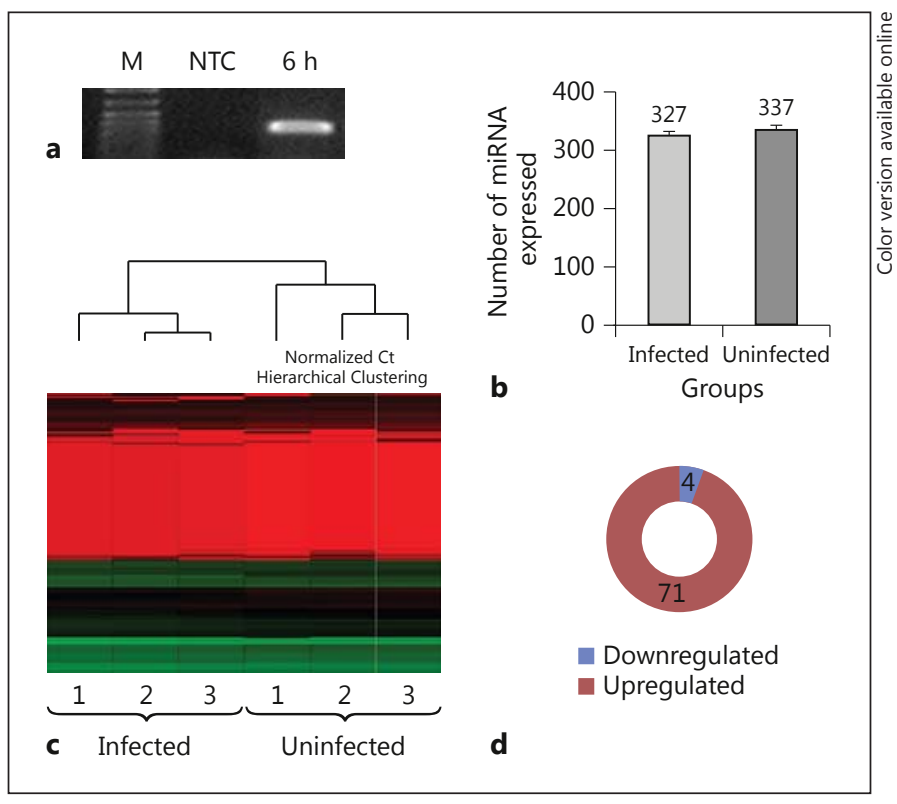

Fig. 3. miRNA expression in CHIKV-infected cells $6 \mathrm{~h}$ after infection. a RT-PCR analysis for CHIKV transcripts in the cells infected with $\mathrm{MOI}=1$ at $6 \mathrm{~h}$ after infection. $\mathbf{b}$ miRNA expression pattern: average number of miRNAs (rounded off to nearest whole number) expressed in the infected and uninfected cells. c Hierarchical clustering of the replicates clearly distinguished the infected group from the uninfected group. d miRNA modulation: only a small number of the miRNAs were found to be downregulated at $6 \mathrm{~h}$ after infection, as the majority of the significantly modulated miRNAs were upregulated after CHIKV infection.

and network analysis also revealed the effect of the significantly modulated miRNAs on the molecules involved in the apoptosis and Jak-STAT signaling pathways (fig. 5).

\section{CHIKV Infection Downregulates Top $2 b$ Expression}

One of the main observations after CHIKV or other alphavirus infection is the inhibition of cell growth and proliferation. Computational analysis of the significantly modulated miRNAs also suggested various cell growth and functional pathways are significant targets of the modulated miRNAs (online suppl. fig. 1). Two of the miRNAs, miR-409-3p and miR-878-3p, which were upregulated after CHIKV infection, were predicted to target Top2b expression (table 2). miR-409-3p is also conserved in humans, whereas miR-878-3p is mouse specific. Expression of these two miRNAs was also validated by the individual qRT-PCR assay (fig. 6). Top2b is a DNA gyrase that plays an important role in cellular growth and replication. Therefore, CHIKV-infected cell lysates were test- 
Fig. 4. Pathway analysis of the significantly modulated miRNAs: miRPath software analysis was done to identify KEGG pathways targeted by the modulated miRNAs. The graph shows KEGG pathways for the cellular signaling and the processes that were predicted to be significantly modulated by the combined effect of the miRNAs. The blue bar (colors in online version only) refers to the number of genes (y-axis) predicted to be targeted by modulated miRNAs under a specific pathway (x-axis). The red bar refers to the number of miRNAs (y-axis) modulated in a specific pathway (x-axis).

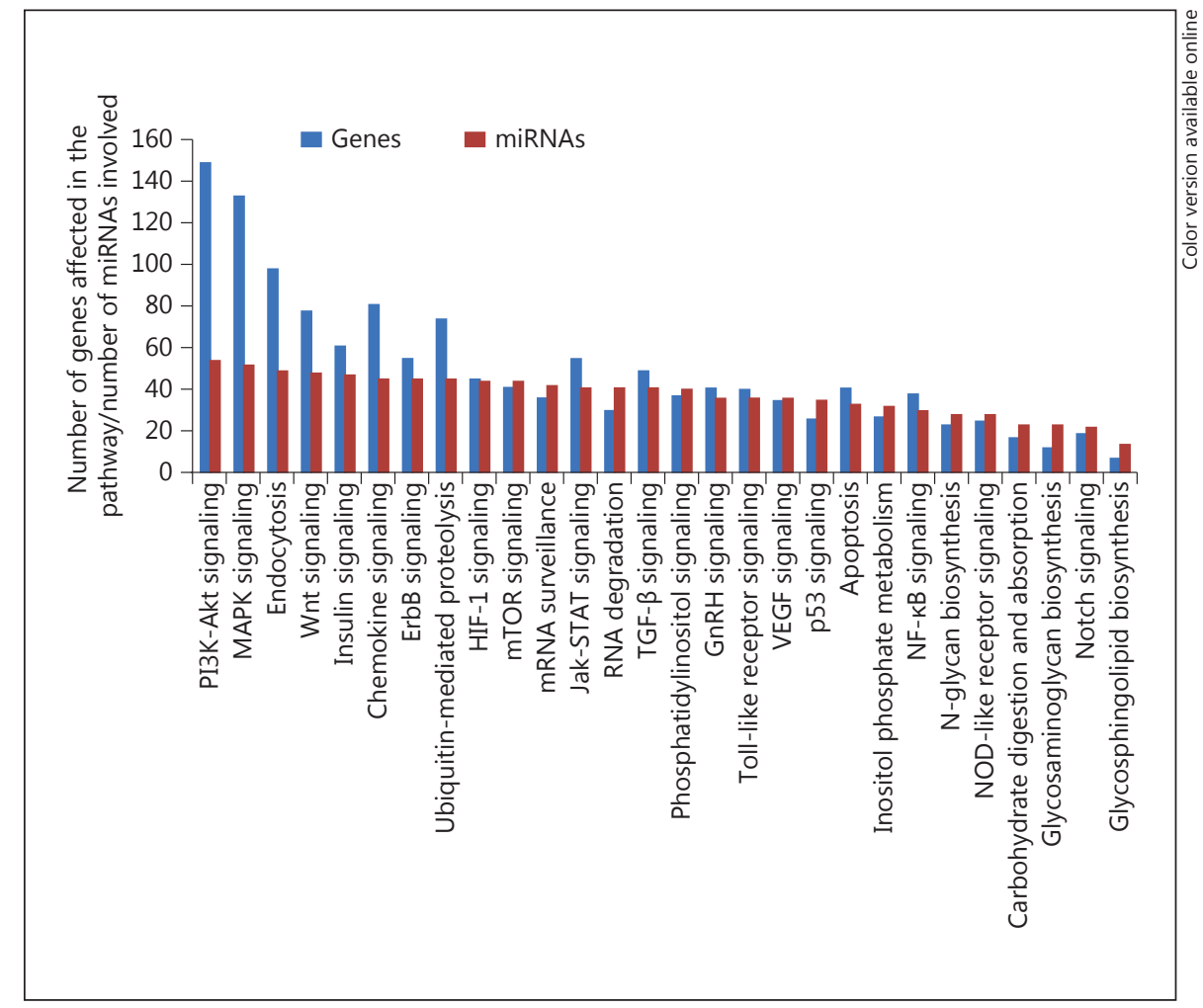

Table 2. TargetScan analysis for identifying predicted targets of miRNAs

\begin{tabular}{ll}
\hline $\begin{array}{l}\text { Position of target nucleotide } \\
\text { of Top2b 3'UTR }\end{array}$ & $\begin{array}{l}\text { Predicted consequential pairing of target } \\
\text { region (top) and miRNA (bottom) }\end{array}$ \\
\hline $\begin{array}{l}\text { 189-195 of Top2b 3'UTR mmu-miR-878-3p } \\
\text { 301-307 of Top2b 3'UTR mmu-miR-409-3p }\end{array}$ & $5^{\prime}$...UUUUACUCAUUGAAAUGUCAUGU... \\
\hline $3^{\prime} \quad$ AGAUGGGUCACACCACAGUACG
\end{tabular}

ed by Western blot analysis for Top2b expression. The cells infected with $\mathrm{MOI}=1$ did not exhibit the downregulation of Top2b (fig. 7a). To check if the initial infectivity dose may affect or enhance the downregulation of Top2b, lysate of the cells infected with MOI = 10 were also tested for Top2b expression. A clear downregulation of Top2b was observed in the cells infected with $\mathrm{MOI}=10$ at 48 and $72 \mathrm{~h}$ after infection (fig. $7 \mathrm{~b}$ ). Active virus replication, but no significant CPE, was observed at 24 and $48 \mathrm{~h}$ after infection in the cells infected with $\mathrm{MOI}=10$ (fig. 1, 2), suggesting that the downregulation of Top2b is induced by the viral infection in the absence of CPE. CPE was evident at $72 \mathrm{~h}$ after infection in the cells infected with MOI $=10$ (fig. 2). Correlation of Top2b downregulation with the induction of cell death was done by observing the alteration in the nucleus morphology of infected cells, a hallmark for the apoptotic nuclei [21]. Only a few nuclei showed altered morphology at 48 and $72 \mathrm{~h}$ after infection in the cells infected with MOI $=1$ (fig. 8). However, alteration in the nuclear morphology was widespread in the cells infected with MOI $=10$ at $48 \mathrm{~h}$ and increased at $72 \mathrm{~h}$ after infection (fig. 8). 
Fig. 5. Apoptotic and Jak-STAT pathway targeted by the modulated miRNAs. Network analysis of the apoptotic pathway (a) and Jak-STAT pathways (b) showed several molecules in these pathways to be targeted by the significantly modulated miRNAs in CHIKV-infected cells.

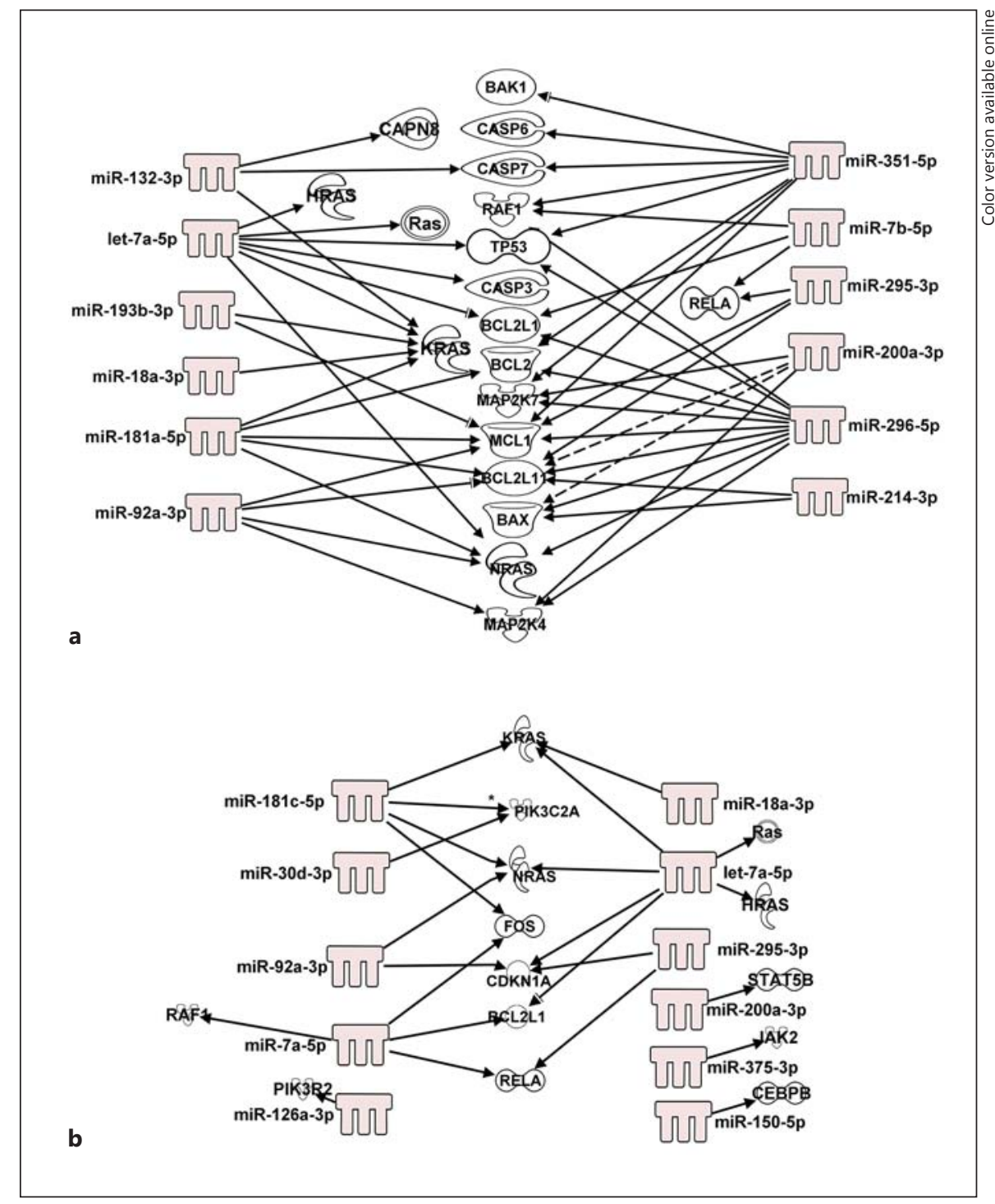

\section{Discussion}

The modulation of the cellular transcription and translation by the New and the Old World alphaviruses is an important mechanism of inhibiting cellular immune response to virus infection and replication $[16,22]$. The New and the Old World alphaviruses have been shown to utilize the capsid and the nonstructural protein 2, respectively, to induce cellular transcriptional shutoff $[22,23]$. The inhibition of the cellular translation via protein kinase R-dependent and -independent mechanisms has been described as a way to inhibit cellular antiviral responses by the alphaviruses [24]. Protein kinase R-independent shutdown of the cellular gene translation by
CHIKV has also been proposed as a mechanism to evade the cellular immune response to the infection [25]. Early events after the infection are critical for inhibiting the cellular immune responses and establishing virus replication [16]. miRNAs, which are endogenous post-transcription/translation inhibitors, have been shown to play an important role in various viral infections. Several DNA viruses and retroviruses are known to code for their own miRNAs or have been shown to modulate the host cellular miRNAs for their replication and disease development [9-14]. On the other hand, alphaviruses, which are the RNA viruses, are not known to encode miRNAs [26]. However, the modulation of the host cellular miRNAs has been shown to contribute to specific cell tropism and 


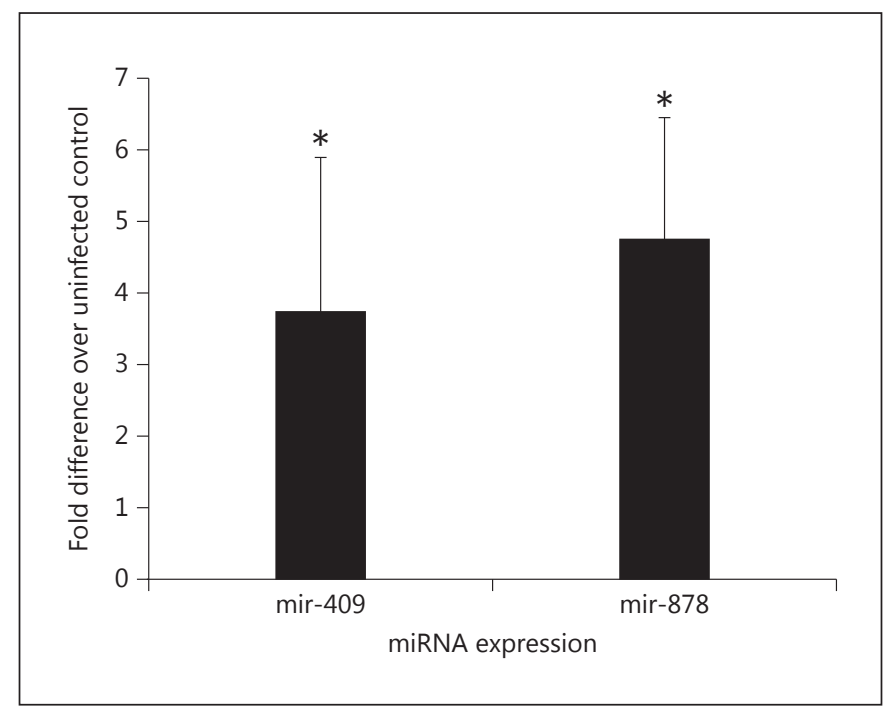

Fig. 6. miRNA expression validation. Two of the miRNAs, mir409-3p and mir-878-3p, which were upregulated in the miRNA array data, were validated by qRT-PCR. Expression of each of the two miRNAs was also found to be upregulated in the infected cells over that of the uninfected cells. Data presented are the fold upregulation $\left( \pm \mathrm{SEM} ;{ }^{*} \mathrm{p}<0.05\right)$ calculated from the mean $\Delta \Delta \mathrm{C}_{\mathrm{t}}$ value obtained from three biological samples for each injury group. Statistical significance was calculated using the individual $\Delta \Delta \mathrm{C}_{t}$ values obtained from the three biological replicates for each of the infected and control groups.

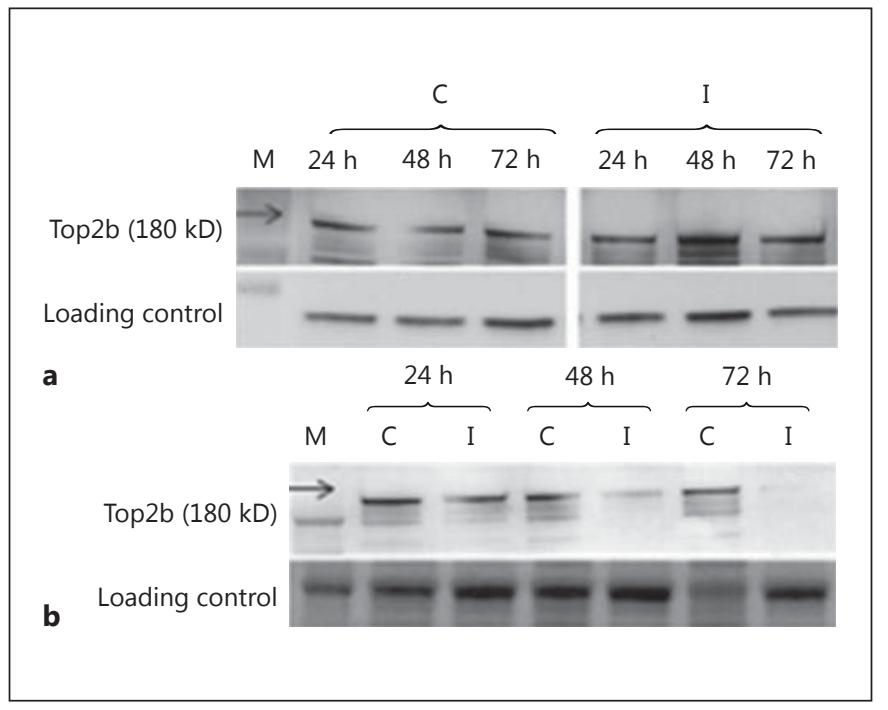

Fig. 7. Top $2 \mathrm{~b}$ expression in CHIKV-infected cells. L cells were infected with $\mathrm{MOI}=1$ or MOI $=10$ of CHIKV, and Top2b expression was analyzed. a No effect on Top2b expression was observed in cells infected with $\mathrm{MOI}=1$. $\mathbf{b}$ A clear downregulation of Top2b was observed in the cells infected with $\mathrm{MOI}=10$ at $48 \mathrm{~h}$, and its expression was negligible at $72 \mathrm{~h}$ after infection. $\mathrm{C}=$ Control uninfected; $\mathrm{I}=$ infected; $\mathrm{M}=$ marker. These results are representative of repeat experiments.
Fig. 8. Nuclear staining of CHIKV-infected cells. Nuclear staining with DAPI was done to identify alteration in the nuclear morphology after CHIKV infection. At MOI = $1(n=3)$, only a few nuclei in the infected cells showed alteration in the morphology of the cellular nuclei (arrows) at 48 and $72 \mathrm{~h}$ after infection as compared to the uninfected cells. At MOI $=10(n=3)$, the number of nuclei with altered morphology increased markedly at $48 \mathrm{~h}$ after infection, which further increased and were more widespread at $72 \mathrm{~h}$ after infection. Also note the marked reduction in the number of cellular nuclei at 48 and $72 \mathrm{~h}$ in infected cells as compared to the uninfected cells $(n=2)$, indicating cell growth arrest in the infected samples. Magnification: objective $\times 40$. These results are representative of a repeat experiment.

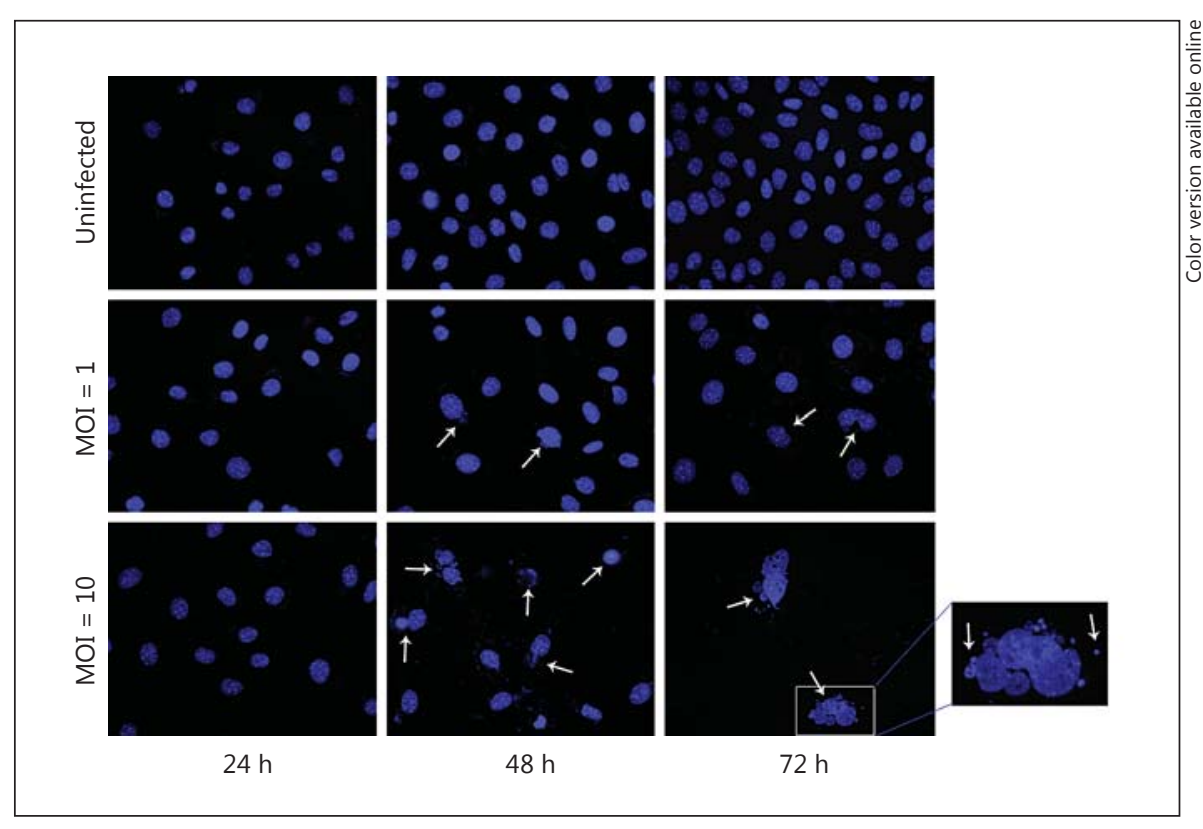

Chikungunya Alters Host miRNA Expression 
response to the infection and disease development of the encephalitic alphaviruses $[8,27]$. Drosha, a critical component of miRNA machinery, has also been shown to be an important modulator of the cellular antiviral response to Sindbis virus infection [28]. Earlier, the cellular miRNA expression response to CHIKV infection was reported at relatively later stages of infection [4]. However, early events within the first few hours of alphavirus infection are crucial in establishing the infection and inhibition of the cellular transcription and translation [16]. Since miRNAs act by modulating the cellular transcription and translation processes, evaluation of the host cellular miRNAs at very early stages of infection warranted further investigation. Inhibition of cellular proliferation or cell growth arrest is commonly observed after alphavirus infections. In this study, inhibition of cell proliferation was also evident in the cells infected with CHIKV (fig. 2, 8). Core analysis showed various cell growth and functional pathways potentially being the significant target of the modulated miRNAs (online suppl. fig. 1). Top2b is a DNA gyrase that is essential in DNA transcription and replication, and therefore essential for cellular growth and replication [29]. MiR-409-3p, which is predicted to target Top2b, is also conserved in the humans. Top $2 \mathrm{~b}$ downregulation and CPE were observed in the cells infected at higher MOI within 48 and $72 \mathrm{~h}$ after infection, respectively, suggesting that the increased initial infectivity dose of CHIKV may enhance the effect of CHIKVinduced cellular transcription shutoff in the cells. CHIKV has also been shown to induce delayed apoptosis and use apoptotic blebs to spread infection to neighboring cells [17-19]. Network analysis of the modulated miRNAs identified several upregulated miRNAs that could potentially modulate the apoptotic pathway (fig. 3). Altered nuclear morphology, which is an indicator of apoptosis in the infected cells, was more pronounced in the cells infected at higher MOI (fig. 5). Though miRNA analysis was done at an early time point after infection, it is not surprising to observe the related phenotypic changes at a later time point in infection, as miRNAs act by posttranscriptional modification and their effect on ongoing or existing housekeeping proteins and cellular processes may not be immediate.

The cellular immune response to viruses encompasses pathways such as the pathogen recognition pathways [e.g. Toll-like receptor (TLR) signaling], and the interferon and cytokine response pathways (e.g. Jak-STAT, Pi3-Akt, mTOR, NF- $\kappa B$, MAPK signaling, etc.). TLR signaling is one of the primary cellular immune responses against alphaviruses [30-32]. CHIKV has been shown to modulate
TLR signaling in patients, and the more replication-competent strain of CHIKV has been shown to induce relatively weak expression of TLRs (TLR 3 and 7) over the less replication-competent strain of CHIKV [33-35]. CHIKV and another closely related alphavirus, the Sindbis virus, have been shown to be resistant to the interferon-induced inhibition by blocking STAT1 phosphorylation and its nuclear translocation [20,36]. CHIKV has also been shown to activate $\mathrm{Pi} 3 / \mathrm{Akt} / \mathrm{mTOR}$ signaling to drive its own replication [37]. Consistent with these observations, TLR, JAK-STAT, Pi3-Akt, mTOR and MAPK signaling pathways were identified to be potentially affected by the modulated miRNAs (fig. 2; online suppl. data set 1). Some of the upregulated miRNAs such as miR-149, miR-150, miR-15b, miR-181a, miR-181c, miR-425 and miR-92a, which are conserved between mice and humans, were also reported to be upregulated in an earlier study [4]. Not surprisingly, some of the modulated pathways such as TGF- $\beta$ signaling, ubiquitin-mediated proteolysis and prion disease (not shown in our data), pathways that were reported by Saxena et al. [4], were also found to be affected in our data analysis.

In conclusion, we described the early stage of miRNA modulation after CHIKV infection. miRNAs that may play a critical role in establishment of CHIKV infection in the host cells by targeting the cellular transcriptional/ translational machinery and the early immune responses were identified. Further studies will be needed to evaluate the role and functions of these miRNAs during CHIKV infection, which may aid in identifying therapeutic targets of CHIKV.

\section{Acknowledgments}

This study was supported by a grant from DTRA. The opinions expressed herein are those of the author(s), and are not necessarily representative of those of the Uniformed Services University of the Health Sciences (USUHS), the Department of Defense (DOD), or the United States Army, Navy or Air Force. The authors would like to acknowledge Dr. Deepti Parashar, National Institute of Virology, Pune, India, for her help with miRNA profiles and Mr. Nikhil Thumar for his help in compilation of the data tables.

\section{Disclosure Statement}

The authors declare no conflict of interest. 


\section{References}

1 Chhabra M, Mittal V, Bhattacharya D, Rana U, Lal S: Chikungunya fever: a re-emerging viral infection. Indian J Med Microbiol 2008; 26:5-12.

2 Assuncao-Miranda I, Cruz-Oliveira C, Da Poian AT: Molecular mechanisms involved in the pathogenesis of alphavirus-induced arthritis. Biomed Res Int 2013;2013:973516.

3 Fischer M, Staples JE; Arboviral Diseases Branch; National Center for Emerging and Zoonotic Infectious Diseases, CDC: Notes from the field: chikungunya virus spreads in the Americas - Caribbean and South America, 2013-2014. MMWR Morb Mortal Wkly Rep 2014;63:500-501.

4 Saxena T, Tandon B, Sharma S, Chameettachal S, Ray P, Ray AR, Kulshreshtha R: Combined miRNA and mRNA signature identifies key molecular players and pathways involved in chikungunya virus infection in human cells. PLoS One 2013;8:e79886.

5 Tsetsarkin KA, Vanlandingham DL, McGee $\mathrm{CE}$, Higgs S: A single mutation in chikungunya virus affects vector specificity and epidemic potential. PLoS Pathog 2007;3:e201.

6 Jaffar-Bandjee MC, Ramful D, Gauzere BA, Hoarau JJ, Krejbich-Trotot P, Robin S, Ribera A, Selambarom J, Gasque P: Emergence and clinical insights into the pathology of chikungunya virus infection. Exp Rev Anti Infect Ther 2010;8:987-996.

7 Das T, Jaffar-Bandjee MC, Hoarau JJ, Krejbich Trotot P, Denizot M, Lee-Pat-Yuen G, Sahoo R, Guiraud P, Ramful D, Robin S, Alessandri JL, Gauzere BA, Gasque P: Chikungunya fever: CNS infection and pathologies of a re-emerging arbovirus. Prog Neurobiol 2010; 91:121-129.

8 Bhomia M, Balakathiresan N, Sharma A, Gupta P, Biswas R, Maheshwari R: Analysis of microRNAs induced by Venezuelan equine encephalitis virus infection in mouse brain. Biochem Biophys Res Commun 2010;395: 11-16.

9 Harwig A, Das AT, Berkhout B: Retroviral microRNAs. Curr Opin Virol 2014;7C:47-54.

10 Hook L, Hancock M, Landais I, Grabski R, Britt W, Nelson JA: Cytomegalovirus microRNAs. Curr Opin Virol 2014;7C:40-46.

11 Jiang X, Kanda T, Wu S, Nakamura M, Miyamura T, Nakamoto S, Banerjee A, Yokosuka O: Regulation of microRNA by hepatitis $B$ virus infection and their possible association with control of innate immunity. World J Gastroenterol 2014;20:7197-7206.

12 Li X, Yang W, Ye W, Jin L, He J, Lou L: MicroRNAs: novel players in hepatitis $\mathrm{C}$ virus infection. Clin Res Hepatol Gastroenterol 2014;38:664-675.

13 Lagatie O, Tritsmans L, Stuyver LJ: The miRNA world of polyomaviruses. Virol J 2013; 10:268.
14 Swaminathan G, Martin-Garcia J, NavasMartin S: RNA viruses and microRNAs: challenging discoveries for the 21st century. Physiol Genomics 2013;45:1035-1048.

15 Vlachos IS, Kostoulas N, Vergoulis T, Georgakilas G, Reczko M, Maragkakis M, Paraskevopoulou MD, Prionidis K, Dalamagas T, Hatzigeorgiou AG: DIANA miRPath v.2.0: investigating the combinatorial effect of microRNAs in pathways. Nucleic Acids Res 2012;40:W498-W504.

16 Frolov I, Akhrymuk M, Akhrymuk I, Atasheva S, Frolova EI: Early events in alphavirus replication determine the outcome of infection. J Virol 2012;86:5055-5066.

17 Joubert PE, Werneke S, de la Calle C, GuivelBenhassine F, Giodini A, Peduto L, Levine B, Schwartz O, Lenschow D, Albert ML: Chikungunya-induced cell death is limited by ER and oxidative stress-induced autophagy. Autophagy 2012;8:1261-1263.

18 Joubert PE, Werneke SW, de la Calle C, Guivel-Benhassine F, Giodini A, Peduto L, Levine B, Schwartz O, Lenschow DJ, Albert ML: Chikungunya virus-induced autophagy delays caspase-dependent cell death. J Exp Med 2012;209:1029-1047.

19 Krejbich-Trotot P, Denizot M, Hoarau JJ, Jaffar-Bandjee MC, Das T, Gasque P: Chikungunya virus mobilizes the apoptotic machinery to invade host cell defenses. FASEB J 2011;25: 314-325.

20 Fros JJ, Liu WJ, Prow NA, Geertsema C, Ligtenberg M, Vanlandingham DL, Schnettler E, Vlak JM, Suhrbier A, Khromykh AA, Pijlman GP: Chikungunya virus nonstructural protein 2 inhibits type I/II interferon-stimulated JAK-STAT signaling. J Virol 2010;84:1087710887.

21 Willingham MC: Cytochemical methods for the detection of apoptosis. J Histochem Cytochem 1999;47:1101-1110.

22 Garmashova N, Gorchakov R, Volkova E, Paessler S, Frolova E, Frolov I: The old world and new world alphaviruses use different virus-specific proteins for induction of transcriptional shutoff. J Virol 2007;81:24722484.

23 Garmashova N, Gorchakov R, Frolova E, Frolov I: Sindbis virus nonstructural protein nsP2 is cytotoxic and inhibits cellular transcription. J Virology 2006;80:5686-5696.

24 Gorchakov R, Frolova E, Williams BR, Rice $\mathrm{CM}$, Frolov I: PKR-dependent and -independent mechanisms are involved in translational shutoff during Sindbis virus infection. J Virol 2004;78:8455-8467.

25 White LK, Sali T, Alvarado D, Gatti E, Pierre P, Streblow D, Defilippis VR: Chikungunya virus induces IPS-1-dependent innate immune activation and protein kinase r-independent translational shutoff. J Virol 2011;85: 606-620.
26 Donaszi-Ivanov A, Mohorianu I, Dalmay T, Powell PP: Small RNA analysis in Sindbis virus infected human HEK293 cells. PLoS One 2013;8:e84070.

27 Trobaugh DW, Gardner CL, Sun C, Haddow $\mathrm{AD}$, Wang E, Chapnik E, Mildner A, Weaver SC, Ryman KD, Klimstra WB: RNA viruses can hijack vertebrate microRNAs to suppress innate immunity. Nature 2014;506:245-248.

28 Shapiro JS, Schmid S, Aguado LC, Sabin LR, Yasunaga A, Shim JV, Sachs D, Cherry S, tenOever BR: Drosha as an interferon-independent antiviral factor. Proc Natl Acad Sci USA 2014;111:7108-7113.

29 Pommier Y: Drugging topoisomerases: lessons and challenges. ACS Chem Biol 2013;8: 82-95.

30 Sharma A, Maheshwari RK: Oligonucleotide array analysis of Toll-like receptors and associated signalling genes in Venezuelan equine encephalitis virus-infected mouse brain. J Gen Virol 2009;90:1836-1847.

31 McKimmie CS, Johnson N, Fooks AR, Fazakerley JK: Viruses selectively upregulate Tolllike receptors in the central nervous system. Biochem Biophys Res Commun 2005;336: 925-933.

32 McKimmie CS, Fazakerley JK: In response to pathogens, glial cells dynamically and differentially regulate Toll-like receptor gene expression. J Neuroimmunol 2005;169:116125.

33 Kashyap RS, Morey S, Bhullar S, Baheti N, Chandak N, Purohit H, Taori G, Daginawala $\mathrm{H}$ : Determination of Toll-like receptor-induced cytokine profiles in the blood and cerebrospinal fluid of chikungunya patients. Neuroimmunomodulation 2014;21:338-346.

34 Priya R, Dhanwani R, Patro IK, Rao PV, Parida MM: Differential regulation of TLR mediated innate immune response of mouse neuronal cells following infection with novel ECSA genotype of chikungunya virus with and without E1:A226V mutation. Infect Genet Evol 2013;20:396-406.

35 Wikan N, Khongwichit S, Phuklia W, Ubol S, Thonsakulprasert T, Thannagith M, Tanramluk D, Paemanee A, Kittisenachai S, Roytrakul S, Smith DR: Comprehensive proteomic analysis of white blood cells from chikungunya fever patients of different severities. J Transl Med 2014;12:96.

36 Simmons JD, Wollish AC, Heise MT: A determinant of Sindbis virus neurovirulence enables efficient disruption of Jak/STAT signaling. J Virol 2010;84:11429-11439.

37 Das I, Basantray I, Mamidi P, Nayak TK, B MP, Chattopadhyay S, Chattopadhyay S: Heat shock protein 90 positively regulates chikungunya virus replication by stabilizing viral non-structural protein nsP2 during infection. PLoS One 2014;9:e100531. 